\title{
MicroRNA High Throughput Loss-of- Function Screening Reveals an Oncogenic Role for miR-21-5p in Hodgkin Lymphoma
}

\author{
Ye Yuan ${ }^{\mathrm{a} e \mathrm{e}}$ Fubiao Niu ${ }^{\mathrm{a}} \quad$ Ilja M. Nolte ${ }^{\mathrm{c}}$ Jasper Koerts ${ }^{\mathrm{a}}$ Debora de Jong ${ }^{\mathrm{a}}$ \\ Bea Rutgers $^{\mathrm{a}} \quad$ Jan Osinga ${ }^{\mathrm{b}} \quad$ Maria Azkanaz $^{\mathrm{b}} \quad$ Martijn Terpstra $^{\mathrm{b}} \quad$ Leonid Bystrykh $^{\mathrm{d}}$ \\ Arjan Diepstra $^{a} \quad$ Lydia Visser $^{\mathrm{a}} \quad$ Agnieszka Dzikiewicz-Krawczyk $^{\dagger} \quad$ Klaas Kok $^{\mathrm{b}}$ \\ Joost Kluiver ${ }^{\mathrm{a}} \quad$ Anke van den Berga

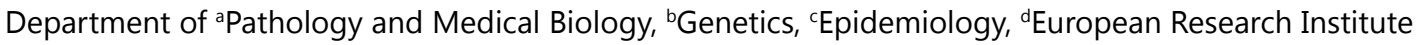 \\ for Biology of Ageing, University of Groningen, University Medical Center Groningen, Groningen, \\ the Netherlands, eDepartment of Clinical Pharmacy, the Second Affiliated Hospital of Harbin Medical \\ University, Harbin, China, fInstitute of Human Genetics, Polish Academy of Sciences, Poznan, Poland
}

\section{Key Words}

Classical Hodgkin lymphoma $(\mathrm{cHL}) \cdot$ High-throughput screen • miR-21-5p • Apoptosis $•$ BTG2 - PELI1

\begin{abstract}
Background/Aims: Classical Hodgkin lymphoma $(\mathrm{cHL})$ is among the most frequent lymphoma subtypes. The tumor cells originate from crippled germinal center (GC)-B cells that escaped from apoptosis. MicroRNAs (miRNAs) play important roles in B-cell maturation and aberrant expression of miRNAs contributes to the pathogenesis of $\mathrm{CHL}$. Our aim was to identify oncogenic miRNAs relevant for growth of $\mathrm{cHL}$ using a high-throughput screening approach. Methods: A lentiviral pool of 63 miRNA inhibition constructs was used to identify miRNAs essential to cell growth in three $\mathrm{cHL}$ cell lines in duplicate. As a negative control we also infected $\mathrm{cHL}$ cell lines with a lentiviral barcoded empty vector pool consisting of 222 constructs. The abundance of individual constructs was followed over time by a next generation sequencing approach. The effect on growth was confirmed using individual GFP competition assays and on apoptosis using Annexin- $V$ staining. Our previously published Argonaute 2 (Ago2) immunoprecipitation (IP) data were used to identify target genes relevant for cell growth / apoptosis. Luciferase assays and western blotting were performed to confirm targeting by miRNAs. Results: Four miRNA inhibition constructs, i.e. miR-449a-5p, miR-625$5 p$, let-7f-2-3p and miR-21-5p, showed a significant decrease in abundance in at least 4 of 6 infections. In contrast, none of the empty vector constructs showed a significant decrease in abundance in 3 or more of the 6 infections. The most abundantly expressed miRNA, i.e. miR-21-5p, showed significantly higher expression levels in CHL compared to GC-B cells. GFP

J. Kluiver and A. van den Berg contributed equally to this work.

Joost Kluiver

and Anke van den Berg

Department of Pathology and Medical Biology, University Medical Center Groningen

Hanzeplein 1, 9700RB, Groningen (The Netherlands)

Tel. +31 50 3619559, Fax +3150 3619107, E-Mail j.I.kluiver@umcg.nl; a.van.den.berg01@umcg.nl
\end{abstract}




\section{Cellular Physiology Cell Physiol Biochem 2018;49:144-159 \begin{tabular}{ll|l} 
DOI: 10.1159/000492850 & $\begin{array}{l}\text { O 2018 The Author(s). Published by S. Karger AG, Basel } \\
\text { www.karger.com/cpb }\end{array}$ \\
\hline and Biochemistry
\end{tabular}

competition assays confirmed the negative effect of miR-21-5p inhibition on HL cell growth. Annexin- $V$ staining of cells infected with miR-21-5p inhibitor indicated a significant increase in apoptosis at day 7 and 9 after viral infection, consistent with the decrease in growth. Four miR21-5p cell growth- and apoptosis-associated targets were AGO2-IP enriched in $\mathrm{CHL}$ cell lines and showed a significant decrease in expression in $\mathrm{CHL}$ cell lines in comparison to normal GC-B cells. For the two most abundantly expressed, i.e. BTG2 and PELI1, we confirmed targeting by miR-21-5p using luciferase assays and for PELI1 we also confirmed this at the protein level by western blotting. Conclusion: Using a miRNA loss-of-function high-throughput screen we identified four miRNAs with oncogenic effects in $\mathrm{CHL}$ and validated the results for the in $\mathrm{CHL}$ abundantly expressed miR-21-5p. MiR-21-5p is upregulated in $\mathrm{CHL}$ compared to GC-B cells and protects $\mathrm{CHL}$ cells from apoptosis possibly via targeting BTG2 and PELI1.

\section{Introduction}

Classical Hodgkin lymphoma (cHL) is a germinal center (GC) B-cell-derived lymphoma subtype accounting for $95 \%$ of all HL cases [1]. It is characterized by a minority of tumor cells - known as Hodgkin Reed-Sternberg (HRS) cells - mixed within an abundant background of reactive immune cells [2]. CHL is sub classified into four histological subtypes, i.e. nodular sclerosis, mixed cellularity, lymphocyte rich, and lymphocyte depleted cases, according to the morphology of the HRS cells and the composition of the cellular background [3].

MicroRNAs (miRNAs) are short non-coding RNA molecules inhibiting gene expression at the post-transcriptional level [4]. Generally, a single miRNA can interact with multiple targets and vice versa [5]. MiRNAs are fundamental to the development of blood cells by regulating almost every stage of hematopoiesis [6]. In addition, miRNAs are important determinants of B-cell development and maturation [7, 8]. Functional studies showed that aberrantly expressed miRNAs can act as oncogenes or tumor suppressor genes [9-12].

Several studies showed aberrant miRNA expression profiles in HL cell lines, total tissues and microdissected HRS cells compared to control cells and tissues [13-20] The primary miR-155 transcript, also known as BIC, was the first miRNA reported to have strongly enhanced expression levels in HL [21]. Although several targets of this oncogenic miRNA have been reported, the HL relevant target genes remain unknown. MiR-135a inhibition led to reduced Bcl-xL via targeting JAK2 [22]. Inhibition of the miR-17/106b seed family resulted in a G1-phase cell cycle arrest by releasing CDKN1A from miRNA-mediated inhibition [23]. $H u R$ and Dicer were shown to be target genes of the oncogenic miR-9 and inhibition of miR9 resulted in higher cytokine production levels [24]. Together these studies clearly showed that miRNAs are important in the pathogenesis of HL.

In this study, we determined effects of miRNA inhibition on cHL cell growth using a high-throughput screen with a pool of miRNA inhibition constructs and a barcoded empty vector pool as a control. This resulted in the identification of miR-21-5p as a miRNA critical to cHL cell growth by inhibiting apoptosis. Insights into the potential mechanism of miR-21$5 p$ were obtained by identifying target genes in our previously published Ago2-IP data [16].

\section{Materials and Methods}

\section{Culturing of cHL and HEK-293T cell lines}

CHL cell lines L540 (nodular sclerosis, T-cell derived), KM-H2 (mixed cellularity), L1236 (mixed cellularity) L428 and L591 (both nodular sclerosis) were cultured in RPMI-1640 medium (Lonza, Breda, The Netherlands), SUPHD1 (nodular sclerosis) in McCoys5A medium (Lonza) and HEK-293T (embryonic kidney) in DMEM (Lonza) at $37^{\circ} \mathrm{C}$ in an atmosphere containing $5 \% \mathrm{CO}_{2}$. Culture medium was supplemented with $2 \mathrm{mM}$ ultraglutamine 1 (Lonza), 100U/ml penicillin/streptomycin and 5\% (L428), 10\% (KM-H2, L1236, L591, SUPHD1 and HEK-293T) or 20\% (L540) fetal bovine serum (FBS) (Lonza). The origin of all cell lines 
was confirmed with STR DNA analysis. Routinely performed mycoplasma tests consistently showed that the cell lines were not contaminated.

Preparation of miRNA inhibition (miRZIP) constructs pool

We included a total of 63 constructs in the pool, these were partly selected based on being highly abundant or differentially expressed in $\mathrm{cHL}$ compared to GC $B$ cells $(n=17)$ [16], and partly included based on availability of constructs $(\mathrm{n}=41 ; 34$ miRNAs with similar expression levels in cHL cell and GC-B cells, 1 miRNA with decreased expression and 6 miRNAs not expressed in cHL) (Table S1). For all supplemental material see www.karger. com/10.1159/000492850 In addition, 5 nontargeting controls were included. The 63 miRZIP constructs were partly obtained from System Biosciences (SBI, Palo Alto, CA) and partly custom made. Custom constructs were generated by ligation of double stranded oligo's antisense/ sense to the miRNA of interest (Integrated DNA technologies, Coralville, Iowa, USA) into the EcoRI and BamHI restriction sites of the miRZIP ${ }^{\mathrm{Tm}} /$ pGreen-Puro Lentiviralbased miRNA inhibition/ shRNA vector (SBI). The insert sequences of the custom constructs are shown in Table S2. In addition to the miRNA inhibition constructs the library also included 186 shRNA inserts targeting genes

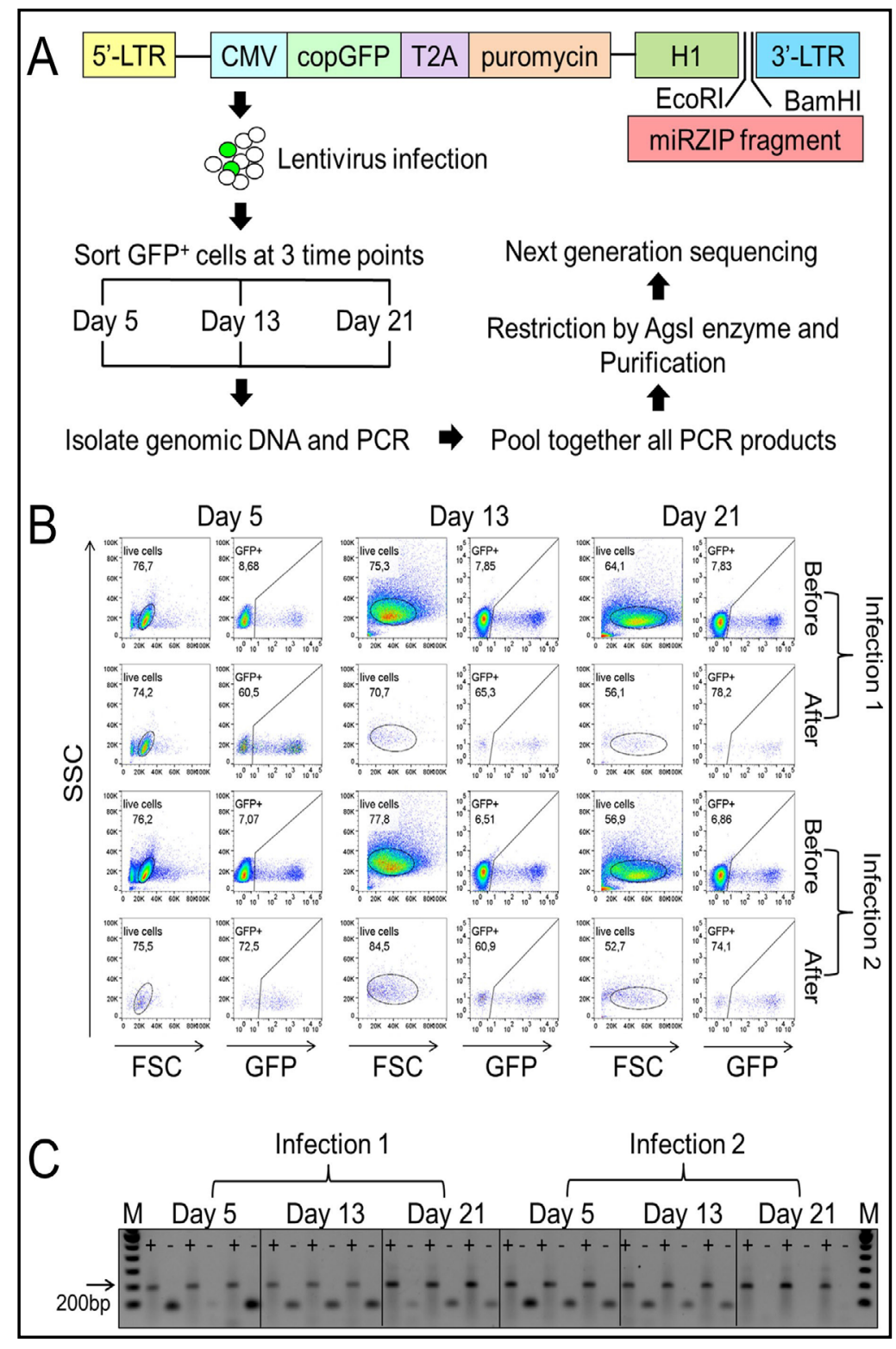

Fig. 1. Overview of the high-throughput loss-of-function screening approach to identify miRNAs which affect cHL growth. (A) Schematic representation of the workflow. The double stranded DNA oligo's were cloned into EcoRI and BamHI restriction sites of the lentiviral miRZIP vector. The lentiviral particles were used to infect the cHL cell lines. Genomic DNA was isolated from $\mathrm{GFP}^{+}$cells sorted at different time points. The inserts were amplified using barcoded primers, pooled based on band intensities and digested with AgsI and then subjected to next generation sequencing. (B) An example of sorting results in $\mathrm{KM}-\mathrm{H} 2$. GFP cells were sorted at day 5, day 13 and day 21 from duplicate infections. (C) Agarose gel electrophoresis of the PCR products of miRZIP infected samples. Sizes of miRZIP PCR products range from 172 to $194 \mathrm{bp} .+$ indicates that genomic DNA was added to the PCR reaction, indicates that no template was added to the PCR reaction (negative control) and $\mathrm{M}$ stands for the $100 \mathrm{bp}$ molecular weight DNA ladder. 


\section{Cellular Physiology Cell Physiol Biochem 2018;49:144-159 \begin{tabular}{l|l|l} 
and Biochemistry Published online: 22 August, 2018 & $\begin{array}{l}\text { @ } 2018 \text { The Author(s). Published by S. Karger AG, Basel } \\
\text { www.karger.com/cpb }\end{array}$ \\
\hline
\end{tabular} \\ Yuan et al.: Oncogenic Role for MiR-21-5p in Hodgkin Lymphoma}

irrelevant for this project. All inserts were sequence verified by Sanger sequencing. A mix containing equal amounts of DNA of each construct was prepared and used for the generation of the lentiviral particles.

\section{Preparation of the barcoded empty vector pool}

The barcodes were designed using a fixed strategy with seven times a variable nucleotide triplet separated by a constant nucleotide doublet. The complementary oligo's were hybridized and ligated into the BsrGI and BamHI restriction sites (located 3'primed of the CMV-TurboGFP cassette) of the lentiviral PeGZ2 vector [25]. In total 222 Sanger sequencing verified barcoded empty vectors were pooled and used for generation of lentiviral particles.

\section{Lentivirus production, infection and sorting}

Lentiviral particles were produced in HEK-293T cells by calcium phosphate precipitation transfection procedure as described previously [16]. CHL cells were transduced with virus in the presence of $4 \mu \mathrm{g} /$ $\mathrm{ml}$ polybrene. For the high throughput screens, 5-8 million cells were infected with a maximal infection percentage of $20 \%$, aiming to infect at least 800,000 unique cells at the start of the experiment with a single construct. At day 5, day 13 and day 21 after infection a total of 5-10 million cells were prepared for sorting, whereas the remainder of the cells ( $>2$ million) was used to continue the culture. $\mathrm{GFP}^{+}$cells were sorted on the MoFlo sorter using a 70- $\mu$ m nozzle (BD Biosciences, San Jose, California, USA).

After infection with the barcoded empty vector pool the GFP percentages varied between $12.2 \%$ and $18.2 \%$ in KM-H2, L540 and L428. After sorting, the percentages of GFP+ cells were all above 57.4\% (Table S3). The GFP percentages obtained after infection with the lentiviral miRNA inhibition pool varied between $7.2 \%$ and $10.1 \%$ in KM-H2, L540 and L428. After sorting of GFP+ cells at indicated time points, the percentages were more than $60 \%$ for all samples (Table S4). The GFP-sorted cells were used for DNA isolation, polymerase chain reaction (PCR), restriction, purification and next generation sequencing (NGS) using the experimental workflow as illustrated in Fig. 1A. A representative example of the GFP analysis before and after sorting is shown in Fig. 1B.

\section{DNA isolation and amplification of the inserts}

Genomic DNA was isolated using a salt/chloroform extraction method. DNA concentration was measured with the NanoDrop ${ }^{\mathrm{TM}} 1000$ Spectrophotometer (Thermo Fisher Scientific Inc., Waltham, Massachusetts, USA) and the quality was checked on a $1 \%$ agarose gel.

Triplicate PCRs were performed using ampliTaq DNA Polymerase kit (Thermo Fisher, Waltham, Massachusetts, USA) using 400ng genomic DNA as input. For the barcoded empty vector (EV-BC) experiment, one universal forward primer (5'-TCTCGGCATGGACGAGCTG-3') with a unique 9nt sample ID was used for each individual PCR in combination with one of the three different reverse primers i.e. BC-rev-L-TIIBC (5'-GGGGGATCGTCACTGGCC-3') used for all L428 samples, BC-revL+1-TIIBC (5'-TGGGGGATCGTCACTGGCC-3') used for all KM-H2 samples and BC-rev-L+2-TIIBC (5'-ATGGGGGATCGTCACTGGCC-3') used for all L540 samples. A similar approach was used for the miRZIP experiments. A universal forward primer (5'- CTGGGAAATCACCATAAACG-3') with a unique 8-9nt sample ID was used for each PCR in combination with the mzip-R+1bp (5'-CTAACCAGAGAGACCCAGTAG-3') reverse primer for all L428 samples, the mzip-R+2bp (5'-TCTAACCAGAGAGACCCAGTAG-3') reverse primer for all L540 samples and with the mzip-R+3bp (5'-GTCTAACCAGAGAGACCCAGTAG-3') reverse primer for all KMH2 samples. An input of approximately 400ng of genomic DNA, equivalent of $\sim 67,000$ cells (assuming $6 \mathrm{pg}$ genomic DNA per cell), was used in each PCR. This corresponds to 40, 000 or more single $\mathrm{GFP}^{+}$cells per PCR for cultures with a purity of GFP+ cells after sorting of at least $60 \%$. All amplifications were performed in triplicate in one run to reduce experimental variation. PCR products were analyzed on $2 \%$ agarose gel and mixed at equal amounts depending on band intensities. An example of the PCR results is shown in Fig. 1C.

Next generation sequencing (NGS)

PCR products were purified by DNA Clean \& Concentrator ${ }^{\mathrm{TM}}-5$ (Zymo Research, Irvine, CA) following the manufacturer's protocol. The PCR product mix of the miRNA inhibitor construct pool was restricted by AgsI enzyme (SibEnzyme, Academtown, Russia), which cuts in the loop sequence resulting in a shorter fragment for NGS. This step is incorporated to avoid sequencing problems that can occur with stem-loop sequences. Restricted PCR products were purified by DNA Clean \& ConcentratorTM-5 (Zymo Research). 


\section{Cellular Physiology Cell Physiol Biochem 2018;49:144-159 \begin{tabular}{l|l|l} 
and Biochemistry Published online: 22 August, 2018 & $\begin{array}{l}\text { @ } 2018 \text { The Author(s). Published by S. Karger AG, Basel } \\
\text { www.karger.com/cpb }\end{array}$ \\
\hline
\end{tabular} \\ Yuan et al.: Oncogenic Role for MiR-21-5p in Hodgkin Lymphoma}

Ligation of adapters was done using the NEBNext Multiplex (\#E7335) oligo's for Illumina (New England biolabs, Ipswich, Massachusetts, USA) following the manufacturer's protocol. Paired-end sequencing was performed using the $\mathrm{MiSeq}^{\mathrm{TM}}$ (Illumina, San Diego, CA). After NGS, the read counts were assigned to a sample using the sample ID followed by alignment to the insert sequences of all constructs in the pools. The alignment was performed using BWA (version 0.7.12; https://github.com/lh3/bwa) and processing of the results was done with SAM tools (version 1.3; http://www.htslib.org/) [26]. We aimed to obtain at least 40, 000 reads per sample, which corresponded to the number of GFP+ cells used as input for the PCR amplification (see above).

\section{$R T-q P C R$}

MiR-21-5p expression levels were measured using the Taqman reverse transcriptase quantitative polymerase chain reaction (RT-qPCR) quantitative PCR assay (\#000397, Thermo Fisher Scientific Inc.) as described previously [27]. Among five housekeeping genes tested (RNU6B, RNU24, RNU44, RNU48 and RNU49), we selected RNU44 (\#001094) for normalization as this gene showed the most stable expression levels between GC-B cells and cHL cell lines (data not shown). Cycle crossing point ( $\mathrm{Cp}$ ) values were determined with the Light Cycler 480 Software (Roche, Basel, Switzerland). Relative expression levels of miRNAs were determined by calculating $2^{-\Delta \mathrm{Cp}}\left(\Delta \mathrm{Cp}=\mathrm{Cp}_{\text {miRNA }}-\mathrm{Cp}_{\mathrm{RNU} 44}\right)$.

\section{GFP competition assay}

CHL cells were infected with miRZIP-21-5p or negative control miRZIP-NT1 lentivirus aiming at an infection percentage of 30-60\%. The cells were cultured for 22 days after infection and the percentage of $\mathrm{GFP}^{+}$cells were monitored triweekly by flow cytometry (BD Biosciences, San Jose, California, USA). The percentage of GFP positive cells at day 4 was set to 1 . All GFP competition assays were performed 3 times.

\section{Apoptosis assay}

CHL cell lines were infected with miR-21-5p inhibitor (miRZIP-21-5p) or negative control miRZIPNT1 cells at a 1:1 ratio (v/v). KM-H2 and L540 were GFP sorted on day 4 to $>95 \%$ purity while L428 were $>95 \%$ GFP+ without sorting. The percentage of apoptotic cells was determined at day 7 and day 9 postinfection. Cells were re-suspended at a concentration of $1 \times 10^{6}$ cells $/ \mathrm{ml}$ in $100 \mu \mathrm{l} 1 \times$ calcium buffer $(2.6 \mu \mathrm{g} /$ $\mathrm{ml} \mathrm{Hepes,} 8.18 \mu \mathrm{g} / \mathrm{ml} \mathrm{NaCl}$ and $0.28 \mu \mathrm{g} / \mathrm{ml} \mathrm{CaCl}_{2}$ ). After staining with Annexin V-APC (BD Biosciences), cells were analyzed by flow cytometry (BD Biosciences).

\section{Prediction of target genes of miRNAs}

Targetscan release 7.0 (http://www.targetscan.org/) was used to generate a list of putative miR-21-5p target genes using cumulative weighted context ${ }^{++}$scores of genes less than or equal to -0.3 [28]. This list was used to identify the miR-21-5p target genes consistently Ago2-IP enriched in at least 2 out of 3 cHL cell lines using our previously published Ago2-IP data in cHL cell lines [16].

\section{Functional annotation analysis}

DAVID bioinformatics Resources 6.7 (https://david.ncifcrf.gov/) was used to functionally annotate genes based on GO category of biological process of GOTERM_BP_FAT.

\section{3'-UTR cloning to luciferase reporter vector, transfection and luciferase assay}

ThemiR-21 bindingsite regions wereamplified using PELI1-Forward: 5'-ACAACTGCCTATTGGTCCCAG-3' withPELI1-Reverse:5'-TTCAGCACTGAGGATAGGTGAT-3' andBTG2-Forward:5'-TATTGCCTTCCCAGACCTGC-3' with BTG2-Reverse: 5'-GGTGTACATTTGTCCATAAGCTGT-3'. Forward primers contained a 5' XhoI site and reverse primers a $5^{\prime}$ NotI site all preceded by 6 random nucleotides to enable efficient digestion. PCR products were digested with XhoI and NotI (New England Biolabs) and cloned into the psi-CHECK-2 vector (Promega, Madison, WI, USA). One million HEK293 cells were transfected with the Amaxa nucleovector device (Lonza) using $2 \mu$ g plasmid, Nucleovector kit V (Lonza) and either $1 \mu \mathrm{M}$ end concentration hsa-miR21-5p pre-miR miRNA precursor (AM17100) or pre-miR miRNA precursor negative controls (AM17110 and AM17111, all Thermo Fischer Scientific Inc.). All transfections were performed six times divided over 3 independent experiments. Cell lysates were made 48 hours after transfection. For each transfection Renilla and Firefly luciferase activity was measured in duplicate using the Dual-Luciferase Reporter Assay System 


\section{Cellular Physiology Cell Physiol Biochem 2018;49:144-159 and Biochemistry \begin{tabular}{l|l} 
DOI: 10.1159/000492850 & (c) 2018 The Author(s). Published by S. Karger AG, Basel \\
www.karger.com/cpb
\end{tabular}

(Promega) according to the manufacturer's instructions. Renilla/Firefly luciferase ratios were calculated and compared to negative control (set to 100\%).

\section{Western blotting}

Infected cells were harvested on day 9 either after sorting (KM-H2 and L540) or directly (L428). Cells were lysed in lysis buffer (\#9803, Cell Signaling Technology, Danvers, Massachusetts, USA) supplemented with PMSF protease inhibitor. Lysates were kept on ice for 45 minutes and centrifuged at $14,000 \mathrm{rpm}$ for 10 minutes at $4^{\circ} \mathrm{C}$ and supernatant was collected. Protein concentration was measured using the BCA Protein Assay Kit (Thermo Fisher Scientific Inc.) following the manufacturer's instructions.

$25 \mu \mathrm{g}$ protein was separated on a polyacrylamide gel and transferred to a nitrocellulose membrane. The membrane was incubated overnight at $4{ }^{\circ} \mathrm{C}$ with primary antibodies diluted in $5 \%$ milk in Tris-buffered saline with Tween-20 (TBST). Primary antibodies used were anti-PELI1 (ab199336, abcam Cambridge, UK) and GAPDH (clone 6C5, Novus Biologicals, Littleton, CO, USA). After secondary or secondary and tertiary antibody steps chemiluminescence was detected with Chemi Doc MP scanner and proteins were visualized and quantified with Image Lab 4.0.1 software (BioRad Hercules, CA, USA). Each infection was performed in duplicate (independent experiments) and analyzed by western blot 2-3 times.

\section{Statistical analysis}

Total read counts per DNA sample of the barcoded EV infected cells varied between 55, 124 and 183, 180 in KM-H2, between 79, 069 and 278, 249 in L540 and between 42, 761 and 217, 973 in L428 (Table S3). For the miRZIP pool, total read counts per sample varied between 35, 819 and 216, 082 in KM-H2, between 33, 272 and 192, 478 in L540 and between 50, 638 and 197, 295 in L428 (Table S4). For both the highthroughput screen of the miRZIP and barcoded empty vector constructs pools, the total read counts per sample were normalized to 40,000. Average read counts of the triplicate PCRs per sample were calculated and constructs with an average read count across all samples of less than 40 were excluded from further analysis. Two hundred and fourteen of the 222 barcoded empty vector constructs had an average normalized read count of 40 or more across all samples. The average normalized read counts of the miRZIP constructs are shown in Fig. 2. Fifty-nine of the 63 constructs had an average normalized read count of 40 or more across all samples. Ratios of the read counts at day 13 and day 21 relative to day 5 were determined for each independent infection. Per construct, the ratios minus 1 were plotted and the slope of the trend line that was forced to 0 was determined using a commercial software package (MATLAB 6.1, The MathWorks Inc., Natick, MA, 2000). An adapted Tukey interquartile (IQR) method with a lower band cutoff of Q1-(1xIQR) and an upper band cutoff of Q3+(1xIQR) was applied to all the slopes to identify constructs that behaved as outliers in the population.

Differences in miR-21-5p expression level between cHL cell lines and GC-B cells were tested using the non-parametric Mann-Whitney test (GraphPad Software Inc., San Diego, CA). Statistical analysis of GFP competition assays was performed as described previously [16]. Briefly, decrease in percentages of $\mathrm{GFP}^{+}$cells over time was compared with the control miRZIP-NT1 using a mixed model with time and the interaction of time and miRNA inhibitor type as fixed effect and measurement repeat within miRNA inhibitor type as random effect in SPSS (22.0.0.0 version, IBM, Armonk, New York, USA). Changes in the normalized Renilla over Firefly luciferase ratios and quantification of the PELI1 western blot were analyzed using a paired t-test. $P$ values $<0.05$ were considered statistically significant. 


\section{Cellular Physiology Cell Physiol Biochem 2018;49:144-159 \begin{tabular}{l|l|l} 
and Biochemistry & DOI: 10.1159/000492850 & $\begin{array}{l}\text { (c) } 2018 \text { The Author(s). Published by S. Karger AG, Basel } \\
\text { www.karger.com/cpb }\end{array}$
\end{tabular} \\ Yuan et al.: Oncogenic Role for MiR-21-5p in Hodgkin Lymphoma}

\section{Results}

\section{Identification of miRNAs that affect cHL cell growth}

A change in relative abundance of specific miRZIP constructs over time implicates that inhibition of the corresponding miRNA either supports or represses growth of cHL. For the empty vector screen, we expect no consistent changes over time. For miRZIP vectors targeting oncogenic miRNAs we expect a decrease in abundance over time, whereas for constructs targeting tumor suppressor miRNAs we expect an increase over time. To determine whether the abundance of a construct changed over time we calculated the slope per construct based on read count fold changes relative to the first measurement (day 5) (Fig. 3 and 4). The high-throughput screen using the barcoded empty vector pool as a control revealed for 12 out of the 214 constructs with sufficient reads a change in relative abundance in the same direction in any 2 of the 6 infections ( $3 \mathrm{cHL}$ cell lines infected in duplicate). None of the EV$\mathrm{BC}$ constructs showed a change in the same direction in 3 or more of the 6 infections. Based on these results we set the minimal criterion for changes to consider as changed in the same direction in at least 4 out of 6 infections for the miRZIP constructs. For the miRZIP control

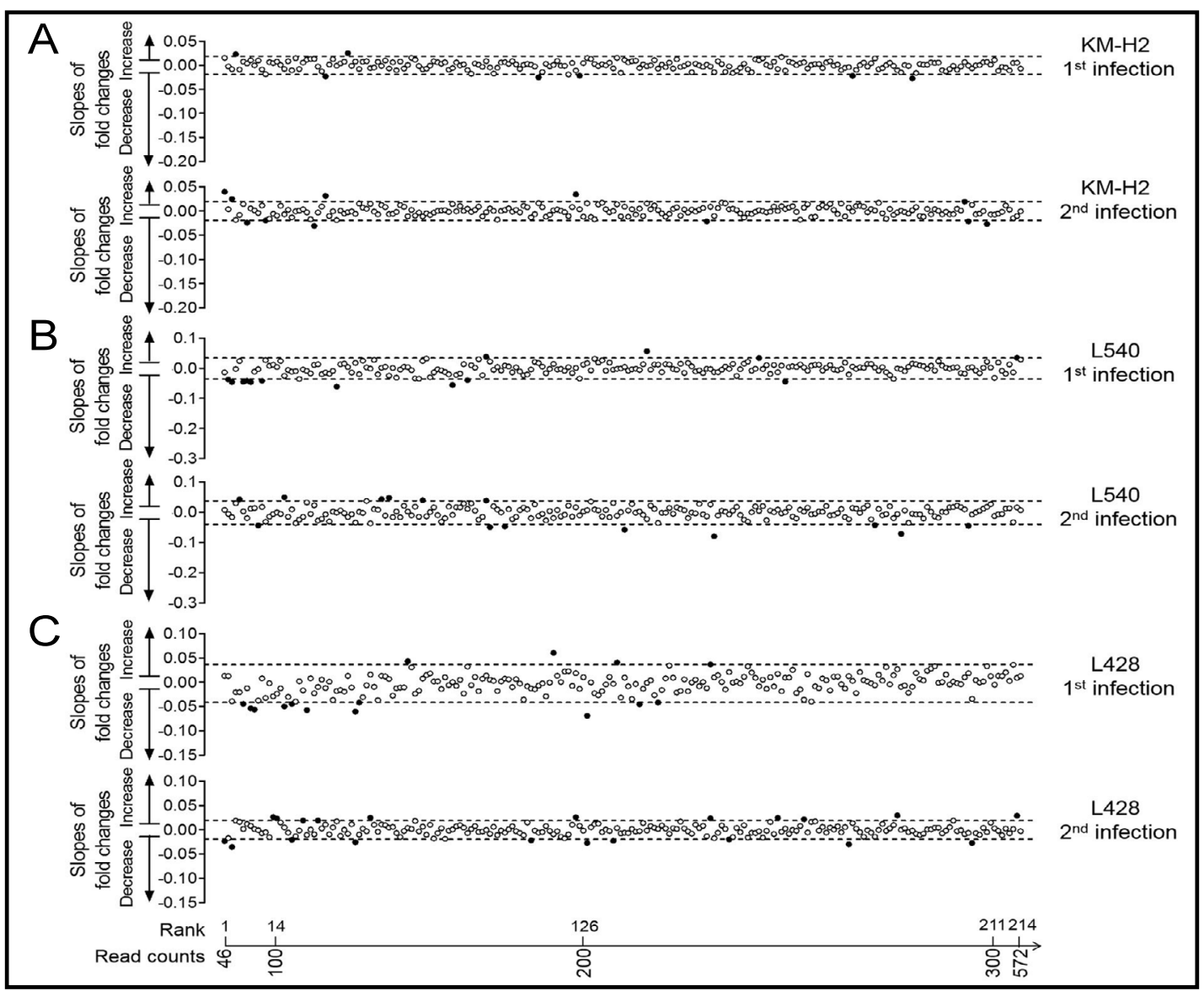

Fig. 3. Schematic representation of the changes in relative abundance of the EV-BC constructs in cHL cell lines. The EV-BC constructs were sorted from low to high based on average reads per construct. Slopes of fold changes calculated based on normalized read counts are shown for both infections in (A) KM-H2: slopes varied between -0.019 and 0.019 in the first and between -0.019 and 0.020 in the second infection; (B) L540: slopes varied between -0.036 and 0.033 in the first infection and between -0.040 and 0.037 in the second infection; and (C) L428: slopes varied between -0.042 and 0.036 in the first infection and between -0.019 and 0.019 in the second infection. The dotted lines indicate the upper and lower boundaries as determined by an adapted Tukey interquartile (IQR) method (see methods). Black dots indicate EV-BC constructs whose abundance changed over time. 


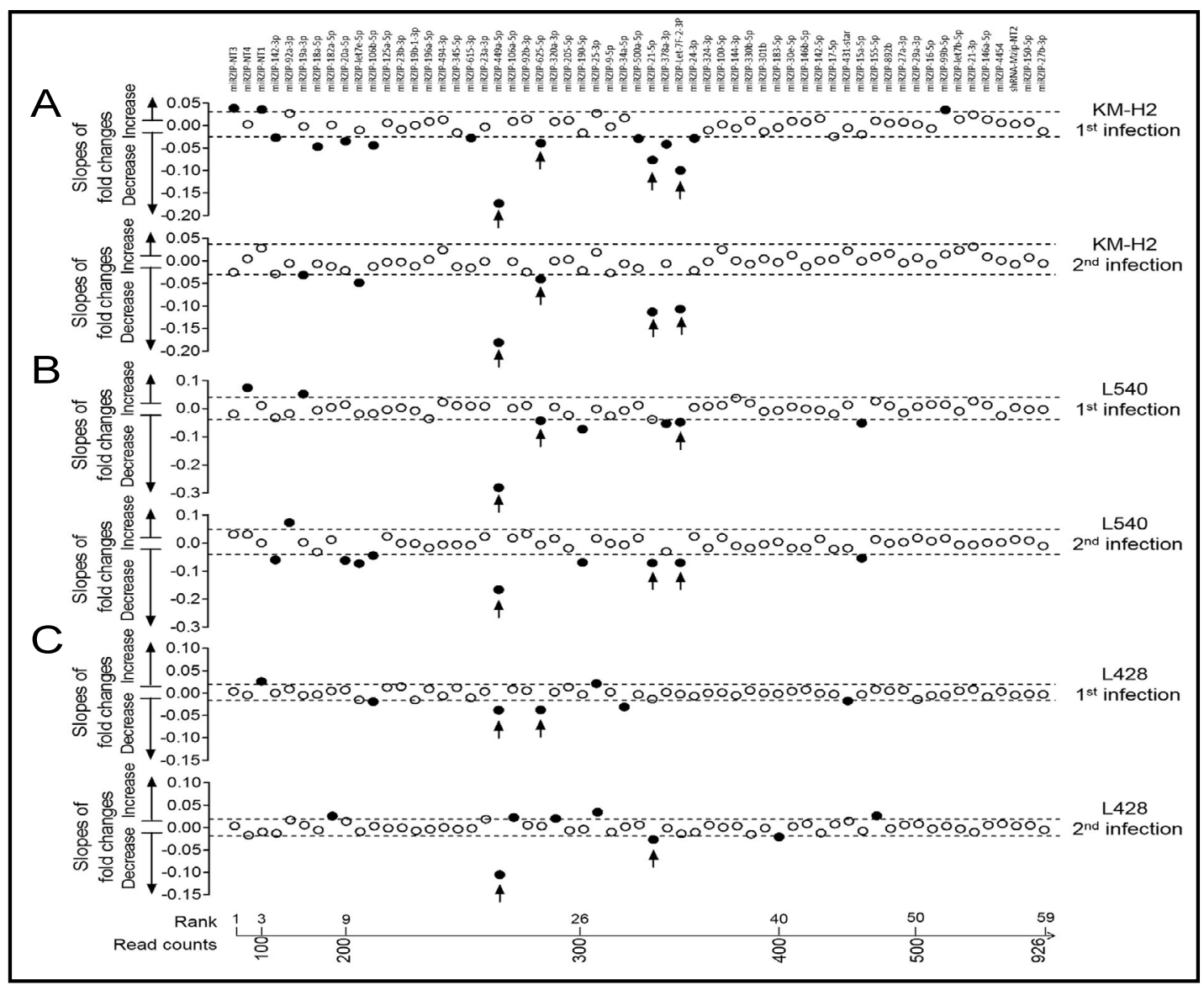

Fig. 4. Schematic representation of the changes in relative abundance of the miRZIP constructs in cHL cell lines. The miRZIP constructs were sorted from low to high based on average reads per construct across all experiments. Slopes of fold changes calculated based on normalized read counts are shown for both infections in (A) KM-H2: the slopes varied between -0.211 and 0.055 in the first and between -0.199 and 0.045 in the second infection; (B) L540: Slopes varied between -0.522 and 0.079 in the first infection and between -0.848 and 0.073 in the second infection; and (C) L428: slopes varied between -0.016 and 0.019 in the first infection and between -0.019 and 0.019 in the second infection. The dotted lines indicate the upper and lower boundaries as determined by an adapted Tukey interquartile (IQR) method. Black dots indicate miRZIP constructs that changed over time and arrows indicate miRZIP constructs that also changed consistently in at least 4 out of 6 infections.

Fig. 5. miR-21-5p is increased in cHL cell lines. Expression levels of the miRNAs identified in the high throughput screen in (A) KM-H2, (B) L540 and (C) L428 cHL cell lines (based on small RNA sequencing data). (D) RT-qPCR validation of miR21-5p in cHL cell lines vs GC-B cells. Significant differences were determined by a Mann-Whitney test. *P $<0.05$. RPM: read counts per million.

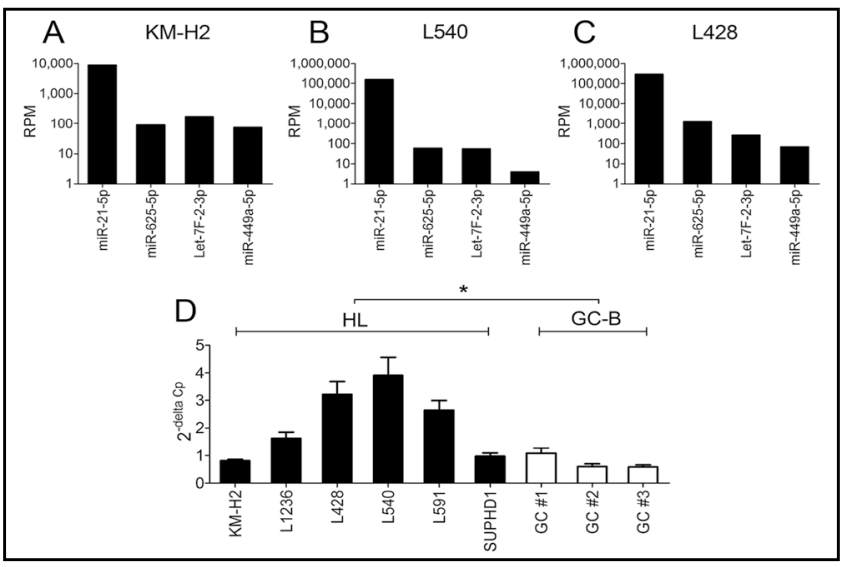


constructs, we observed an increase of miRZIP-NT3 in one infection in KM-H2 and of NT1, NT4 and NT5 an increase in abundance in one of the two infections for two cell lines (note that for NT2 the read counts were too low). For the miRZIP constructs we observed for 12 and 6 a decrease and for 3 and 0 an increase in abundance in KM-H2; for 6 and 9 a decrease and for 2 and 1 an increase in L540; and for 5 and 3 a decrease and for 2 and 5 an increase in L428, for the 2 infections, respectively (Fig. 4). Four miRZIP constructs were depleted in at least 4 of 6 infections done in the 3 cHL cell lines, i.e. miRZIP-449a-5p, miRZIP-625$5 p$, miRZIP-let-7f-2-3p and miRZIP-21-5p. None of the constructs were enriched over time in at least 4 of the 6 infections. In addition, miRZIP-106b-5p was decreased in 3 of the 6 infections and miRZIP-190-5p, miRZIP-142-3p and miRZIP-20a-5p were decreased in 2 of the 6 infections, but as we set our threshold to 4 we did not follow them up.

\section{MiR-21-5p acts as an oncogene in $c H L$}

We used our previously published small RNA sequencing data [16] to study the expression levels of the $4 \mathrm{miRNAs}$ that were the top candidates from our miRZIP screen, i.e. miRZIP-449a-5p, miRZIP-625-5p, miRZIP-let-7f-2-3p and miRZIP-21-5p. We observed the highest expression levels for miR-21-5p in the $3 \mathrm{cHL}$ cell lines used in the screen (Fig. 5A-C). The other 3 miRNAs showed approximately 100-fold lower expression levels in the cHL cell lines. Therefore, we selected miR-21-5p for our follow-up experiments. RT-qPCR revealed that the miR-21-5p levels were significantly increased in cHL cell lines compared to GC-B cells (Fig. 5D). The two mixed cellularity cHL cell lines, KM-H2 and L1236, had somewhat lower levels as compared to 3 of the 4 nodular sclerosis cHL cell lines.

Inhibition of miR21-5p resulted in a significant decrease in the percentage of $\mathrm{GFP}^{+}$cells over time in all three cHL cell lines, consistent with the screen (Fig. 6A). The strongest effect was seen in KM-H2 cells, which also showed a significant decrease in construct abundance in both independent infections. To establish the cause of the decrease in $\mathrm{GFP}^{+}$cells, miRZIP-21-5p infected cells were stained with the apoptosis marker Annexin-V. This revealed a significant increase in the percentage of apoptotic cells in all tested $\mathrm{cHL}$ cell lines at day 7 and 9 (Fig. 6B and 6C). No effect was observed on the distribution of the cell cycle phases (data not shown).

Table 1. Ago2-IP enriched probes corresponding to predicted/proven miR21-5p target genes in cHL cell lines. Genes related to cell growth or apoptosis are shown in bold. Expression values are log2 transformed, fold changes are absolute values

\begin{tabular}{|c|c|c|c|c|c|c|c|}
\hline \multirow{2}{*}{ Probe Name } & \multirow{2}{*}{ GeneSymbol } & \multirow{2}{*}{ Targetscan } & \multirow{2}{*}{ Proven targets } & \multicolumn{3}{|c|}{ Fold enrichment (FE) IP/Total } & \multirow{2}{*}{ Avg FE } \\
\hline & & & & КМ-H2 & L428 & L540 & \\
\hline A_23_P87879 & CD69 & $\sqrt{ }$ & & 40.4 & 5.2 & & 22.8 \\
\hline A_24_P373152 & CFL2 & $\sqrt{ }$ & & 27.7 & 12.3 & 26.7 & 22.3 \\
\hline A_23_P46812 & СРЕВ3 & $\sqrt{ }$ & & 27.6 & 7.5 & 15.9 & 17.0 \\
\hline A_23_P62901 & BTG2 & & $\sqrt{ }$ & 10.7 & 22.3 & 14.4 & 15.8 \\
\hline A_23_P49759 & CCL1 & $\sqrt{ }$ & & 5.2 & 18.3 & 16.2 & 13.2 \\
\hline A_23_P95930 & HMGA2 & & $\sqrt{ }$ & 15 & & 8.6 & 11.8 \\
\hline A_24_P358868 & ZNF728 & $\sqrt{ }$ & & 8.9 & 4.4 & 18.5 & 10.6 \\
\hline A_23_P206018 & TPM1 & & $\sqrt{ }$ & & 3.9 & 13.3 & 8.6 \\
\hline A_23_P156310 & SKP2 & $\sqrt{ }$ & & 3.8 & 11.8 & 9.2 & 8.3 \\
\hline A_33_P3691916 & FAM13A & $\checkmark$ & & 1.7 & 4.4 & 18.4 & 8.1 \\
\hline A_23_P410625 & ZNF367 & $\checkmark$ & & 9.2 & 7.6 & 5.8 & 7.5 \\
\hline A_33_P3233764 & LATS1 & & $\sqrt{ }$ & & 4.8 & 10 & 7.4 \\
\hline A_24_P44462 & TPM1 & & $\checkmark$ & & 2.6 & 10.1 & 6.4 \\
\hline A_23_P411612 & SPRYD4 & & $\sqrt{ }$ & 4.2 & 8.5 & 5.9 & 6.2 \\
\hline A_23_P94095 & ANKRD46 & & $\checkmark$ & 5.3 & 7 & 6 & 6.1 \\
\hline A_33_P3335966 & TPM1 & & $\checkmark$ & & 2.7 & 9.4 & 6.0 \\
\hline A_24_P328492 & SOCS5 & $\checkmark$ & & 6.2 & 4.2 & 7.2 & 5.9 \\
\hline A_32_P183218 & ZNF367 & $\checkmark$ & & & 4.9 & 6.1 & 5.5 \\
\hline A_32_P178945 & YOD1 & $\checkmark$ & & 5.2 & 5.3 & & 5.2 \\
\hline A_32_P25737 & CHIC1 & $\sqrt{ }$ & & 7.2 & 2.5 & & 4.9 \\
\hline A_24_P46953 & SGK3 & $\sqrt{ }$ & & & 2.4 & 7 & 4.7 \\
\hline A_33_P3215093 & CHIC1 & $\sqrt{ }$ & & 5.7 & 2.8 & 3.8 & 4.1 \\
\hline A_33_P3400547 & MED21 & $\sqrt{ }$ & & 3.3 & 4.3 & 3.4 & 3.7 \\
\hline A_23_P325631 & SKI & $\sqrt{ }$ & & 4.4 & 2.8 & 3.7 & 3.6 \\
\hline A_23_P217609 & RPL36A & $\checkmark$ & & 2 & 2.7 & 5.7 & 3.5 \\
\hline A_23_P93562 & SESN1 & $\sqrt{ }$ & & 1.8 & 2.8 & 5.2 & 3.3 \\
\hline A_23_P83028 & RECK & $\sqrt{ }$ & $\sqrt{ }$ & & 4 & 2.5 & 3.3 \\
\hline A_23_P339773 & TPRG1L & $\sqrt{ }$ & & 3.4 & 3.5 & 2.5 & 3.1 \\
\hline A_23_P55518 & SMAD7 & $\sqrt{ }$ & $\sqrt{ }$ & 3 & 2.9 & 2.9 & 2.9 \\
\hline A_32_P101689 & FAM3C & $\sqrt{ }$ & & 2 & 2.7 & 3.9 & 2.9 \\
\hline A_33_P3320548 & NUPL2 & $\checkmark$ & & 3.3 & 3 & 2 & 2.8 \\
\hline A_23_P22350 & GRAMD3 & $\checkmark$ & & 2.9 & 2.7 & & 2.8 \\
\hline A_24_P271363 & CDS2 & & $\checkmark$ & 4.2 & 2 & 1.6 & 2.6 \\
\hline A_33_P3398862 & RHOB & & $\sqrt{ }$ & & 2.7 & 2.3 & 2.5 \\
\hline A_33_P3316928 & PELI1 & $\sqrt{ }$ & $\checkmark$ & 1.6 & 2.7 & 2.9 & 2.4 \\
\hline A_23_P9823 & MLXIP & & $\sqrt{ }$ & 1.7 & 2.6 & 2.9 & 2.4 \\
\hline A_33_P3423859 & PPP1R3D & $\sqrt{ }$ & & 2.1 & 3 & 2.2 & 2.4 \\
\hline A_23_P32913 & ARMC10 & $\sqrt{ }$ & & 1.7 & 2.4 & 2.8 & 2.3 \\
\hline A_33_P3213432 & ARMC10 & $\sqrt{ }$ & & 1.7 & 2.5 & 2.6 & 2.3 \\
\hline A_33_P3381751 & TIAM1 & & $\sqrt{ }$ & 2.2 & -1.1 & 5.2 & 2.1 \\
\hline A_23_P154894 & CSTB & $\sqrt{ }$ & & 2.3 & 2.2 & 1.6 & 2.0 \\
\hline
\end{tabular}


Fig. 6. Inhibition of miR-21-5p in cHL decreases cell growth and induces apoptosis. (A) GFP competition assay of miR-21-5p inhibitor (miRZIP-21$5 p)$ and control miRZIP-NT1 infected cHL cell lines L428, L540 and KM-H2. MiRZIP-21-5p was stably transfected in cells using a lentiviral vector, which co-expresses GFP. The GFP percentage was measured triweekly for 22 days and the percentage at the first day of measurement (day 4) was set to 1. (B) Examples of the Annexin V flow cytometry graphs of the apoptosis test done at day 9 after inhibition of miR-21-5p in three cHL cell lines. (C) Overview of the percentages of Annexin $\mathrm{V}$ positive cells at day 7 (open circles) and day 9 (closed circles) of 2 independent experiments in three cHL cell lines. Asterisks indicate significant differences between miR-21-5p inhibitor and miRZIP-NT1. * $\mathrm{P}<0.05$; ${ }^{* *} \mathrm{P}<0.01 ;{ }^{* * *} \mathrm{P}<0.001$.

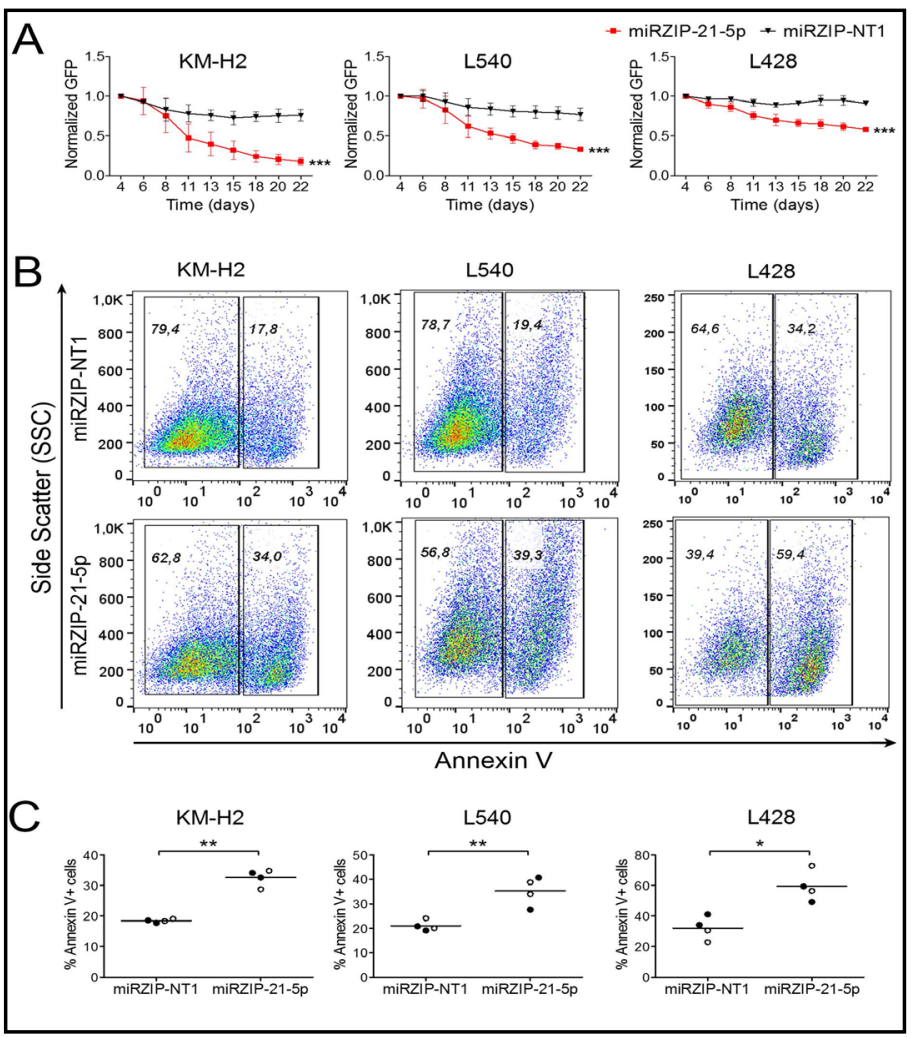

Fig. 7. Identification of miR-21-5p target genes. (A) Ago2-IP enriched mRNA probes per cell line (FC of $\mathrm{IP} / \mathrm{T}>2)$ and the 1,664 probes $(1,294$ genes $)$ that are IP-enriched in at least 2 of the $3 \mathrm{cHL}$ cell lines (indicated by a red triangle). (B) Comparison of the percentage of probes for predicted/proven target genes of miR-21-5p within all expressed and within Ago2IP enriched in cHL. (C) 13/36 proven/predicted miR-21-5p target genes were related to cell growth. Significant differences

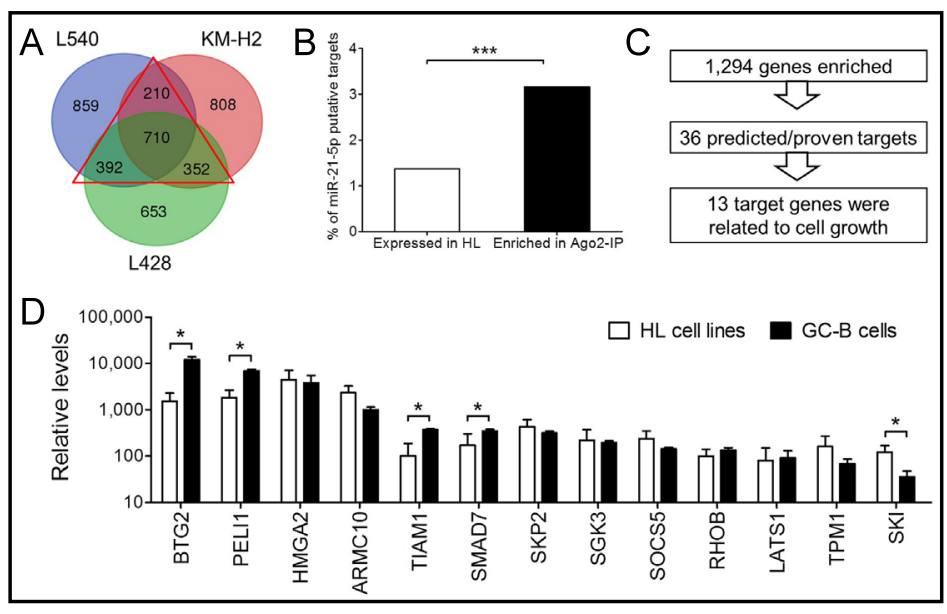
were determined by a Chi-squared test and are marked with asterisks. ${ }^{* * *} \mathrm{P}<0.001$. T: total cell lysate; Ago2-IP: Ago2 immune precipitated fraction. (D) Relative expression levels of 13 proven/predicted miR-21-5p target genes in GC-B cells and cHL cell lines. The order of genes is based on average relative expression in GC-B cells. CHL cell lines include KM-H2, L1236, L428, L540 and SUPHD1. Differences in expression levels were assessed using the nonparametric Mann-Whitney U test. ${ }^{*} \mathrm{P}<0.05$.

\section{Identification and validation of miR-21-5p target genes}

In our previously generated Ago2-RIP chip data of cHL cell lines [16], we identified 1, 294 unique protein coding genes (represented by 1,664 probes) that were Ago2-IP enriched in at least 2 of the $3 \mathrm{cHL}$ cell lines that showed a prominent negative effect on cell growth upon miR-21 inhibition (Fig. 7A). Within the 1, 294 Ago2-IP enriched genes we identified 
26 genes that were proven miR-21-5p targets and 13 Targetscan predicted miR21-5p targets (of which 3 were in overlap with the proven, Table 1). This was a highly significant enrichment of miR-21-5p target genes in the Ago2IP fraction compared to all miR-21-5p target genes present among all genes expressed in the $\mathrm{cHL}$ cell lines (Fig. 7B). Gene ontology analysis revealed that 13 of these 36 Ago2-IP enriched target genes had a function related to cell growth and apoptosis (Fig. 7C and Table 1). Analysis of our previously published microarray data in GC-B cells and cHL cell lines [29], showed a significantly decreased gene expression level in cHL cell lines compared to GC-B cells for 4 genes i.e. BTG2 (B-cell translocation gene 2), PELI1 (E3 Ubiquitin-Protein Ligase Pellino Homolog 1), TIAM1 (T-Cell Lymphoma Invasion And Metastasis 1) and $S M A D 7$, whereas 1 gene, i.e. $S K I$, showed an increased expression in cHL
Fig. 8. BTG2 and PELI1 are direct miR-21-5p targets. (A) Luciferase reporter assays confirm targeting of miR-21-5p to the 3'-UTR of BTG2 and PELI1. Plotted are the normalized Renilla (R) over Firefly (F) luciferase ratios as detected in lysates of HEK293 cells transfected with psiCHECK-2 constructs in combination with miR-21 precursor (miR-21) or control precursor
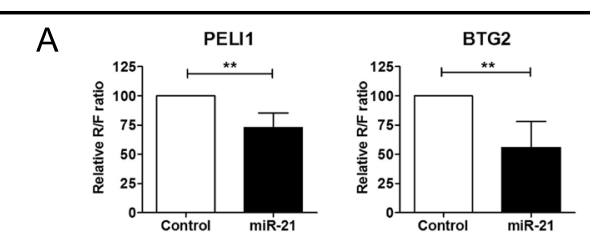

B
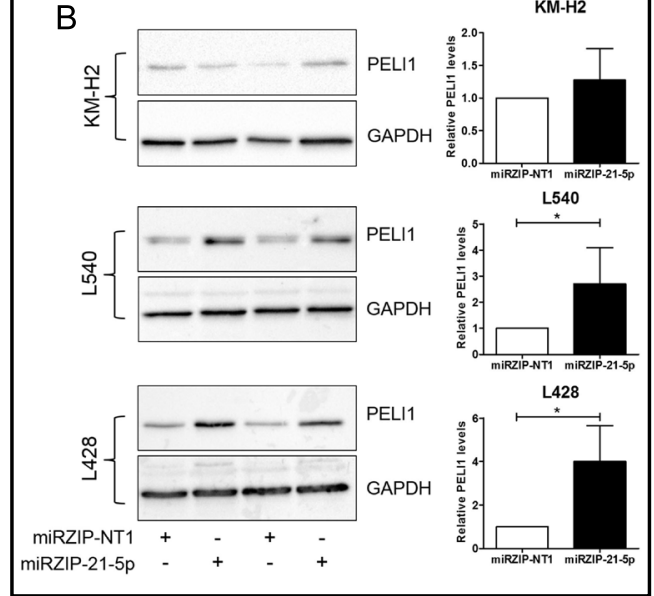

(control). Shown

is the mean with SD. Each luciferase experiment was performed six times divided over three independent experiments. Statistical analysis was performed using a one-tailed paired t-test ${ }^{* *} \mathrm{P}<0.01$. (B) PELI1 protein levels increase upon miR-21-5p inhibition. Left panel shows representative examples of the western blot results of miRZIP-21-5p and control infected cHL cell lines. GAPDH was used as internal control and the PELI1 to GAPDH ratio in control-infected cells was set to 1 . Right panel shows the summary of the quantification of the PELI1 level changes upon miR-21-5p inhibition. Each infection was performed in two independent experiments and each experiment was quantified by western blot 2-3 times. Statistical analysis was performed using a onetailed paired t-test ${ }^{*} \mathrm{P}<0.05$.

(Fig. 7D). The other 8 genes showed no differences in expression levels between cHL cell lines and GC-B cells. BTG2 and PELI1 expression levels were highest in GC-B cells and were considered as the most likely relevant targets for the observed phenotype.

\section{PELI1 and BTG2 are direct targets of miR-21-5p}

To confirm targeting of BTG2 and PELI1 by miR-21-5p we performed luciferase reporter assays using HEK293 cells. Co-transfection of the BTG2 and PELI1 3'-UTR containing luciferase reporter constructs with miR-21-5p revealed on average a $44 \%$ and $27 \%$ reduction in Renilla over Firefly ratio compared to control, respectively (Fig. 8A). This confirmed targeting by miR-21-5p for both genes. In line with these findings, a significant increase in PELI1 protein levels was observed in miR-21 inhibitor infected L540 and L428 cells as compared to control infected cells. For KM-H2 cells we did not observe a significant downregulation (Fig. 8B). Despite testing several antibodies, we were not able to obtain reliable western blotting results for BTG2. 


\section{Cellular Physiology Cell Physiol Biochem 2018;49:144-159 \\ and Biochemistry Published online: 22 August, 2018 \begin{tabular}{l|l} 
DOI: 10.1159/000492850 2018 The Author(s). Published by S. Karger AG, Basel \\
www.karger.com/cpb
\end{tabular} \\ Yuan et al.: Oncogenic Role for MiR-21-5p in Hodgkin Lymphoma}

\section{Discussion}

In this study, we identified miRNAs that promote cHL cell growth using a miRNA inhibitor construct library in combination with a high throughput NGS approach. Four miRZIP constructs were depleted in at least 4 of 6 infections, whereas none of the miRZIP constructs was consistently increased. This bias towards constructs with decreased abundance is consistent with the selection of miRNAs being mostly known oncogenic miRNAs or miRNAs with high expression levels in cHL. We used a barcoded empty vector pool as a control and showed that constructs at most changed in the same direction in 2 of the 6 infections. We selected miR-21-5p for further studies based on its high expression and significantly increased levels in cHL compared to normal GC-B cells. Inhibition of miR-21-5p in a single construct infection experiment confirmed the effect on cell growth based on the significant reduction in $\mathrm{GFP}^{+}$cells over time in all $3 \mathrm{cHL}$ cell lines. This decrease in cell growth was at least in part caused by an increase in apoptosis.

Constructs for seven of the top-10 miRNAs most abundantly expressed in cHL were included in the high-throughput screen, i.e. miR-21-5p, miR-92a-3p, miR-142-5p, miR-155$5 p$, miR-30e-5p, miR-27b-3p and miR-181a-5p. We observed an effect only for the miRZIP21-5p construct and not for the other highly abundant miRNAs. The lack of significant effects for these miRNAs might have been caused by our experimental set-up. As cHL cell lines have a relative high population doubling time, the follow-up of 3 weeks might not have been long enough to identify all constructs that induce cell growth related effects in cHL. On the other hand, the lack of an effect might also be the result of an incomplete inhibition of the miRNAs by the inhibitor constructs, especially for the highly abundant miRNAs. In a previous study we have shown that miR-24-3p inhibition resulted in a decrease in cell growth in L428 and KM-H2 and a significant decrease of cell growth was seen for miR-27a-3p inhibition in L540 [16]. In this study, miRZIP-24-3p was decreased only in 1 infection in KM-H2, whereas miRZIP-27a-3p had no effect in L540. Although we do not have a clear explanation for this discrepancy, it might be related to differences in data analysis and the approach to identify significant differences, which are more robust for individual GFP competition assays.

Four miRNA inhibition constructs were depleted in at least 4 out of 6 infections in three cHL cell lines i.e. miR-449a-5p, miR-625-5p, let-7f-2-3p and miR-21-5p. Our previously published small RNA-seq indicated that for 3 of these miRNAs read counts were less than 500 indicating low expression in cHL [16]. The levels of miR-449a-5p and let-7f-2-3p were higher than the levels of their seed family members, i.e. miR-449b-5p and miR-449c-5p for miR-449a-5p and let-7a-3p, let-7b-3p, let-7f-1-3p, let-7e-3p and let-7a-2-3p for let-7f-2-3p (no miRNAs with the same seed for miR-625-5p). These seed family members could possibly also be inhibited by the miRNA inhibitor constructs targeting miR-449a-5p and let-7f-2$3 p$, but based on their much lower expression levels it seems unlikely that this causes the observed effects on cell growth. In addition, miR-34 members also have the same seed as miR-449a-5p, but the 3-primed ends of the mature miRNAs are less homologous to miR449a. Moreover, the miR-34a inhibitor construct that was also present in our library did not show any effects in the screen. Together, this makes it unlikely that the effect of the miR-449a inhibitor is caused by inhibition of members of the miR-34 family. Analysis of the Ago2IP data revealed 89,37 and 27 predicted target genes for miR-625-5p, miR-449a-5p and let-7f-2-3p, respectively. For let-7f-2-3p, it was not a significant enrichment compared to all expressed genes. For the other 2 miRNAs, the potential target genes were significantly enriched in the IP fraction. The high abundance, differential expression and target gene enrichment in the Ago2-IP fraction together made miR-21-5p the most promising candidate oncogenic miRNA of the 4 that were identified in the screen.

Of the final list of 13 miR-21 targets that were Ago2-IP enriched in cHL, mRNA levels of BTG2 and PELI1 were most abundant in normal GC-B cells and their levels decreased significantly in cHL. This made them attractive candidates for follow-up studies. Indeed, we confirmed binding of miR-21-5p to the 3'-UTR of both genes by luciferase reporter assays. For PELI1, we were able to further confirm this at the protein level by western blot for 2 


\section{Cellular Physiology Cell Physiol Biochem 2018;49:144-159 \begin{tabular}{ll|l} 
DOI: 10.1159/000492850 & $\begin{array}{l}\text { O 2018 The Author(s). Published by S. Karger AG, Basel } \\
\text { www.karger.com/cpb }\end{array}$
\end{tabular}

out of $3 \mathrm{cHL}$ cell lines tested. MiR-21 was previously shown to directly target the tumor suppressor gene BTG2 in HepG2 liver cancer cells [30] and following exposure to N-methyl$\mathrm{N}$-nitro-N'-nitrosoguanidine (MNNG) also in gastric cancer [31]. BTG2 is a known tumor suppressor in B-cell malignancies and acts as an important regulator of B-cell differentiation [32]. Targeting of PELI1 by miR-21 was shown in liver cells, and this interaction played a role in liver regeneration [33]. PELI1 is an E3 ubiquitin ligase that catalyzes the formation of Lys48 (K48) and K63 ubiquitin chains. PELI1-mediated K48 ubiquitination of the NF- $\mathrm{KB}$ subunit c-Rel led to its degradation and negatively regulated T-cell activation [34]. A similar mechanism might apply to $\mathrm{cHL}$, which is characterized by constitutive activation of NF- $\mathrm{KB}$ [35]. PELI1 was shown to promote lymphomagenesis by K63 ubiquitination of BCL6, which resulted in enhanced BCL6 levels [36]. BCL6 protein expression is often negative in CHL [38], which is in line with low PELI1 and high miR-21-5p levels as observed in our study. PELI1 protein levels were low or undetectable in primary cHL tissues and low in cHL cell lines compared to Burkitt lymphoma and diffuse large B-cell lymphoma cell lines [37]. Two additional miR-21-5p targets also showed decreased expression in cHL as compared to GC-B cells, i.e. SMAD7 and TIAM1. MiR-21 was shown to target SMAD7 in endothelial cells [39] and in colorectal cancer cells [40]. SMAD7 protects B-lymphocytes from transforming growth factor (TGF)-beta induced growth inhibition and apoptosis [41]. TIAM1, a guanidine exchange factor of the Rac GTPase, is a validated target gene of miR-21 in colon carcinoma cells [42]. No evidence has been reported of any effects of TIAM1 on pathogenesis of B-cell lymphomas.

An oncogenic role for miR-21-5p has been shown in many types of cancers e.g. breast cancer [43, 44], non-small cell lung cancer [45] and nasopharyngeal carcinoma [46]. In diffuse large B-cell lymphoma (DLBCL), miR-21-5p directly targeted FOXO1 and subsequently inhibited transcription of Bim, which led to downregulation of PTEN. This resulted in an activation of the PI3K/AKT/mTOR pathway, which further decreased FOXO1 expression [47]. However, FOXO1 was not enriched in the Ago2-IP fractions of cHL cell lines.

In line with our finding that miR-21-5p levels were increased in cHL cell lines compared to sorted GC B-cells, others showed elevated miR-21-5p levels in cHL tissues and cell lines compared to reactive lymph nodes. Moreover, miR-21-5p expression was validated in primary HRS cells by in situ hybridization [18]. Although we observed lower levels of miR-21-5p in mixed cellularity compared to nodular sclerosis cHL cell lines, this was not supported by a previous study showing similar miR-21-5p levels in nodular sclerosis and mixed cellularity cell lines and cHL total tissues [18]. More recently, plasma miR-21-5p levels were identified as a potential circulating biomarker in cHL patients $[48,49]$. A moderate increase in apoptosis has been reported upon miR-21-5p inhibition in L428 cells. Pretreatment with miR-21-5p inhibitors sensitized L428 cells to doxorubicin treatment presumably due to decreased BCL2/BAX and BCL2L1/BAX ratios caused by miR-21-5p inhibition [20]. Overall, our findings further support the oncogenic properties of miR-21-5p and show its relevance for $\mathrm{cHL}$ growth.

In summary, using an NGS-based high-throughput screen, we identified oncogenic effects on cHL cell growth for 4 miRNAs. One of these miRNAs, miR-21-5p, was upregulated in cHL compared to GC-B cells and protected cHL cells from apoptosis. Thirteen miR-21$5 p$ target genes enriched in the Ago2-IP fraction had a function related to cell growth and apoptosis of which BTG2 and PELI1 were validated by luciferase reporter assay and PELI1 also by western blot. These two targets are likely to be relevant for the phenotype observed in cHL upon miR-21-5p inhibition.

\section{Acknowledgements}

Y.Y. received a fellowship of the Graduate School of Medical Sciences (GSMS) of the University of Groningen. 


\section{Cellular Physiology Cell Physiol Biochem 2018;49:144-159 \begin{tabular}{ll|l} 
DOI: 10.1159/000492850 & $\begin{array}{l}\text { O } 2018 \text { The Author(s). Published by S. Karger AG, Basel } \\
\text { www.karger.com/cpb }\end{array}$
\end{tabular}

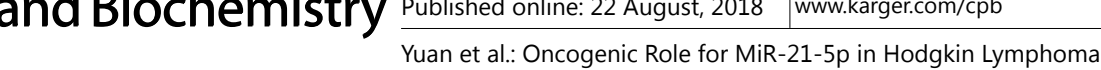

\section{Disclosure Statement}

The authors declare to have no competing interests.

\section{References}

$>1$ Vardiman JW: The World Health Organization (WHO) classification of tumors of the hematopoietic and lymphoid tissues: an overview with emphasis on the myeloid neoplasms. Chem Biol Interact 2010;184:1620.

2 Kanzler H, Kuppers R, Hansmann ML, Rajewsky K: Hodgkin and Reed-Sternberg cells in Hodgkin's disease represent the outgrowth of a dominant tumor clone derived from (crippled) germinal center B cells. J Exp Med 1996;184:1495-1505.

3 Agostinelli C, Pileri S: Pathobiology of hodgkin lymphoma. Mediterr J Hematol Infect Dis 2014;6:e2014040.

4 Zhang B, Pan X, Cobb GP, Anderson TA: microRNAs as oncogenes and tumor suppressors. Dev Biol 2007;302:1-12.

5 Bartel DP: MicroRNAs: target recognition and regulatory functions. Cell 2009;136:215-233.

6 Vasilatou D, Papageorgiou S, Pappa V, Papageorgiou E, Dervenoulas J: The role of microRNAs in normal and malignant hematopoiesis. Eur J Haematol 2010;84:1-16.

7 de Yebenes VG, Bartolome-Izquierdo N, Ramiro AR: Regulation of B-cell development and function by microRNAs. Immunol Rev 2013;253:25-39.

8 Koralov SB, Muljo SA, Galler GR, Krek A, Chakraborty T, Kanellopoulou C, Jensen K, Cobb BS, Merkenschlager M, Rajewsky N, Rajewsky K: Dicer ablation affects antibody diversity and cell survival in the B lymphocyte lineage. Cell 2008;132:860-874.

- Esquela-Kerscher A, Slack FJ: Oncomirs - microRNAs with a role in cancer. Nat Rev Cancer 2006;6:259-269.

-10 Manikandan J, Aarthi JJ, Kumar SD, Pushparaj PN: Oncomirs: the potential role of non-coding microRNAs in understanding cancer. Bioinformation 2008;2:330-334.

11 Hammond SM: MicroRNAs as oncogenes. Curr Opin Genet Dev 2006;16:4-9.

12 Peng Y, Croce CM: The role of MicroRNAs in human cancer. Signal Transduct Target Ther 2016;1:15004.

-13 Van Vlierberghe P, De Weer A, Mestdagh P, Feys T, De Preter K, De Paepe P, Lambein K, Vandesompele J, Van Roy N, Verhasselt B, Poppe B, Speleman F: Comparison of miRNA profiles of microdissected Hodgkin/ Reed-Sternberg cells and Hodgkin cell lines versus CD77+ B-cells reveals a distinct subset of differentially expressed miRNAs. Br J Haematol 2009;147:686-690.

14 Landgraf P, Rusu M, Sheridan R, Sewer A, Iovino N, Aravin A, Pfeffer S, Rice A, Kamphorst AO, Landthaler M, Lin C, Socci ND, Hermida L, Fulci V, Chiaretti S, Foa R, Schliwka J, Fuchs U, Novosel A, Muller RU et al.: A mammalian microRNA expression atlas based on small RNA library sequencing. Cell 2007;129:1401-1414.

15 Gibcus JH, Tan LP, Harms G, Schakel RN, de Jong D, Blokzijl T, Moller P, Poppema S, Kroesen BJ, van den Berg A: Hodgkin lymphoma cell lines are characterized by a specific miRNA expression profile. Neoplasia 2009;11:167-176.

-16 Yuan Y, Kluiver J, Koerts J, de Jong D, Rutgers B, Abdul Razak FR, Terpstra M, Plaat BE, Nolte IM, Diepstra A, Visser L, Kok K, van den Berg A: miR-24-3p Is Overexpressed in Hodgkin Lymphoma and Protects Hodgkin and Reed-Sternberg Cells from Apoptosis. Am J Pathol 2017;187:1343-1355.

17 Cordeiro A, Monzo M, Navarro A: Non-Coding RNAs in Hodgkin Lymphoma. Int J Mol Sci 2017;18:1154.

-18 Navarro A, Gaya A, Martinez A, Urbano-Ispizua A, Pons A, Balague O, Gel B, Abrisqueta P, Lopez-Guillermo A, Artells R, Montserrat E, Monzo M: MicroRNA expression profiling in classic Hodgkin lymphoma. Blood 2008;111:2825-2832.

19 Paydas S, Acikalin A, Ergin M, Celik H, Yavuz B, Tanriverdi K: Micro-RNA (miRNA) profile in Hodgkin lymphoma: association between clinical and pathological variables. Med Oncol 2016;33:34.

20 Sanchez-Espiridion B, Martin-Moreno AM, Montalban C, Figueroa V, Vega F, Younes A, Medeiros LJ, Alves FJ, Canales M, Estevez M, Menarguez J, Sabin P, Ruiz-Marcellan MC, Lopez A, Sanchez-Godoy P, Burgos F, Santonja C, Lopez JL, Piris MA, Garcia JF: MicroRNA signatures and treatment response in patients with advanced classical Hodgkin lymphoma. Br J Haematol 2013;162:336-347. 


\section{Cellular Physiology Cell Physiol Biochem 2018;49:144-159 \begin{tabular}{l|l} 
DOI: 10.1159/000492850 & $\begin{array}{l}\text { O } 2018 \text { The Author(s). Published by S. Karger AG, Basel } \\
\text { wwww.karger.com/cpb }\end{array}$
\end{tabular}

-21 Kluiver J, Poppema S, de Jong D, Blokzijl T, Harms G, Jacobs S, Kroesen BJ, van den Berg A: BIC and miR155 are highly expressed in Hodgkin, primary mediastinal and diffuse large B cell lymphomas. J Pathol 2005;207:243-249.

-22 Navarro A, Diaz T, Martinez A, Gaya A, Pons A, Gel B, Codony C, Ferrer G, Martinez C, Montserrat E, Monzo M: Regulation of JAK2 by miR-135a: prognostic impact in classic Hodgkin lymphoma. Blood 2009;114:2945-2951.

23 Gibcus JH, Kroesen BJ, Koster R, Halsema N, de Jong D, de Jong S, Poppema S, Kluiver J, Diepstra A, van den Berg A: MiR-17/106b seed family regulates p21 in Hodgkin's lymphoma. J Pathol 2011;225:609-617.

-24 Leucci E, Zriwil A, Gregersen LH, Jensen KT, Obad S, Bellan C, Leoncini L, Kauppinen S, Lund AH: Inhibition of miR-9 de-represses HuR and DICER1 and impairs Hodgkin lymphoma tumour outgrowth in vivo. Oncogene 2012;31:5081-5089.

25 Verovskaya E, Broekhuis MJ, Zwart E, Ritsema M, van Os R, de Haan G, Bystrykh LV: Heterogeneity of young and aged murine hematopoietic stem cells revealed by quantitative clonal analysis using cellular barcoding. Blood 2013;122:523-532.

-26 Li H, Handsaker B, Wysoker A, Fennell T, Ruan J, Homer N, Marth G, Abecasis G, Durbin R, Genome Project Data Processing S: The Sequence Alignment/Map format and SAMtools. Bioinformatics 2009;25:20782079.

27 Kluiver J, Slezak-Prochazka I, van den Berg A: Studying microRNAs in lymphoma. Methods Mol Biol 2013;971:265-276.

28 Agarwal V, Bell GW, Nam JW, Bartel DP: Predicting effective microRNA target sites in mammalian mRNAs. Elife 2015;4:e05005.

29 Tayari MM, Winkle M, Kortman G, Sietzema J, de Jong D, Terpstra M, Mestdagh P, Kroese FG, Visser L, Diepstra A, Kok K, van den Berg A, Kluiver J: Long Noncoding RNA Expression Profiling in Normal B-Cell Subsets and Hodgkin Lymphoma Reveals Hodgkin and Reed-Sternberg Cell-Specific Long Noncoding RNAs. Am J Pathol 2016;186:2462-2472.

30 Mao B, Xiao H, Zhang Z, Wang D, Wang G: MicroRNA21 regulates the expression of BTG2 in HepG2 liver cancer cells. Mol Med Rep 2015;12:4917-4924.

-31 Yang Q Xu E, Dai J, Wu J, Zhang S, Peng B, Jiang Y: miR-21 regulates N-methyl-N-nitro-N'-nitrosoguanidineinduced gastric tumorigenesis by targeting FASLG and BTG2. Toxicol Lett 2014;228:147-156.

-32 Tijchon E, van Emst L, Yuniati L, van Ingen Schenau D, Havinga J, Rouault JP, Hoogerbrugge PM, van Leeuwen FN, Scheijen B: Tumor suppressors BTG1 and BTG2 regulate early mouse B-cell development. Haematologica 2016;101:e272-276.

33 Marquez RT, Wendlandt E, Galle CS, Keck K, McCaffrey AP: MicroRNA-21 is upregulated during the proliferative phase of liver regeneration, targets Pellino-1, and inhibits NF-kappaB signaling. Am J Physiol Gastrointest Liver Physiol 2010;298:G535-541.

34 Chang M, Jin W, Chang JH, Xiao Y, Brittain GC, Yu J, Zhou X, Wang YH, Cheng X, Li P, Rabinovich BA, Hwu P, Sun SC: The ubiquitin ligase Peli1 negatively regulates T cell activation and prevents autoimmunity. Nat Immunol 2011;12:1002-1009.

-35 Weniger MA, Kuppers R: NF-kappaB deregulation in Hodgkin lymphoma. Semin Cancer Biol 2016;39:3239.

-36 Park HY, Go H, Song HR, Kim S, Ha GH, Jeon YK, Kim JE, Lee H, Cho H, Kang HC, Chung HY, Kim CW, Chung DH, Lee CW: Pellino 1 promotes lymphomagenesis by deregulating BCL6 polyubiquitination. J Clin Invest 2014;124:4976-4988.

37 Choe JY, Park M, Yun JY, Na HY, Go H, Kim HJ, Oh S, Kim JE: PELI1 expression is correlated with MYC and BCL6 expression and associated with poor prognosis in diffuse large B-cell lymphoma. Mod Pathol 2016;29:1313-1323.

38 Bai M, Panoulas V, Papoudou-Bai A, Horianopoulos N, Kitsoulis P, Stefanaki K, Rontogianni D, Agnantis NJ, Kanavaros P: B-cell differentiation immunophenotypes in classical Hodgkin lymphomas. Leuk Lymphoma 2006;47:495-501.

39 Luo M, Tan X, Mu L, Luo Y, Li R, Deng X, Chen N, Ren M, Li Y, Wang L, Wu J, Wan Q: MiRNA-21 mediates the antiangiogenic activity of metformin through targeting PTEN and SMAD7 expression and PI3K/AKT pathway. Sci Rep 2017;7:43427. 


\section{Cellular Physiology Cell Physiol Biochem 2018;49:144-159 \begin{tabular}{l|l|l} 
DOI: 10.1159/000492850 & $\begin{array}{l}\text { O 2018 The Author(s). Published by S. Karger AG, Basel } \\
\text { www.karger.com/cpb }\end{array}$
\end{tabular} \\ Yuan et al.: Oncogenic Role for MiR-21-5p in Hodgkin Lymphoma}

40 Wang H, Nie L, Wu L, Liu Q, Guo X: NR2F2 inhibits Smad7 expression and promotes TGF-beta-dependent epithelial-mesenchymal transition of CRC via transactivation of miR-21. Biochem Biophys Res Commun 2017;485:181-188.

41 Patil S, Wildey GM, Brown TL, Choy L, Derynck R, Howe PH: Smad7 is induced by CD40 and protects WEHI 231 B-lymphocytes from transforming growth factor-beta -induced growth inhibition and apoptosis. J Biol Chem 2000;275:38363-38370.

42 Cottonham CL, Kaneko S, Xu L: miR-21 and miR-31 converge on TIAM1 to regulate migration and invasion of colon carcinoma cells. J Biol Chem 2010;285:35293-35302.

-43 Frankel LB, Christoffersen NR, Jacobsen A, Lindow M, Krogh A, Lund AH: Programmed cell death 4 (PDCD4) is an important functional target of the microRNA miR-21 in breast cancer cells. J Biol Chem 2008;283:1026-1033.

44 Yan LX, Huang XF, Shao Q Huang MY, Deng L, Wu QL, Zeng YX, Shao JY: MicroRNA miR-21 overexpression in human breast cancer is associated with advanced clinical stage, lymph node metastasis and patient poor prognosis. RNA 2008;14:2348-2360.

45 Zhang JG, Wang JJ, Zhao F, Liu Q, Jiang K, Yang GH: MicroRNA-21 (miR-21) represses tumor suppressor PTEN and promotes growth and invasion in non-small cell lung cancer (NSCLC). Clin Chim Acta 2010;411:846-852.

46 Ou H, Li Y, Kang M: Activation of miR-21 by STAT3 induces proliferation and suppresses apoptosis in nasopharyngeal carcinoma by targeting PTEN gene. PLoS One 2014;9:e109929.

-47 Go H, Jang JY, Kim PJ, Kim YG, Nam SJ, Paik JH, Kim TM, Heo DS, Kim CW, Jeon YK: MicroRNA-21 plays an oncogenic role by targeting FOXO1 and activating the PI3K/AKT pathway in diffuse large B-cell lymphoma. Oncotarget 2015;6:15035-15049.

48 Jones K, Nourse JP, Keane C, Bhatnagar A, Gandhi MK: Plasma microRNA are disease response biomarkers in classical Hodgkin lymphoma. Clin Cancer Res 2014;20:253-264.

-49 van Eijndhoven MA, Zijlstra JM, Groenewegen NJ, Drees EE, van Niele S, Baglio SR, Koppers-Lalic D, van der Voorn H, Libregts SF, Wauben MH, de Menezes RX, van Weering JR, Nieuwland R, Visser L, van den Berg A, de Jong D, Pegtel DM: Plasma vesicle miRNAs for therapy response monitoring in Hodgkin lymphoma patients. JCI Insight 2016;1:e89631. 